\title{
Correction to: Astronautics
}

\section{Correction to: \\ U. Walter, Astronautics, https://doi.org/10.1007/978-3-319-74373-8}

The original version of the book was inadvertently published with the following errors, which have now been corrected:

Insertion or deletion of variables, symbols in equations updated on pp. 34 (Chapter 1), 74 (Chapter 4), 231 (Chapter 7), 245 (Chapter 7), 607 (Chapter 12), 609 (Chapter 12), 623 (Chapter 12), 644 (Chapter 12), 795 (Chapter 16).

A superfluous zero that appeared in the value of the Earth's mean equatorial radius has been removed (63780.1363 $\mathrm{km}$ corrected to $6378.1363 \mathrm{~km}$ on p. 174, Chapter 7).

A superfluous zero in the expression " $g_{0}=90.798$ " has been removed (it is corrected as $g_{0}=9.798$ on p. 123 , Chapter 6).

Repeated text deleted and new text inserted on p. 585 (Chapter 12).

Cross citations of equations are changed on pp. 391 (Chapter 9), 394 (Chapter 9), 489 (Chapter 10), 631 (Chapter 12).

Figures $7.13,8.22,8.37,11.15,12.2$ are replaced with updated figures.

The updated online version of this book can be found at https://doi.org/10.1007/978-3-31974373-8 